\title{
A CASE OF SUDDEN DEATH FOLLOWING MINOR INTENTIONAL TRAUMA; PATHOLOGIST'S CONTRIBUTION IN THE DECISION ON THE MANNER OF DEATH
}

\author{
Kitulwatte I.D.G \\ Department of Forensic Medicine, Faculty of Medicine, \\ University of Kelaniya,Ragama
}

\section{INTRODUCTION}

Sudden death following trauma arouses a huge public interest. This in turn leads the investigators to take stern actions at the outset. Thorough postmortem examination by a pathologist is an essential part of the medico-legal investigation of such deaths. A seemingly direct violence related death can end up as a natural death at the end of the post-mortem examination ${ }^{1}$. Similarly there can be limitations to the opinions that can be expressed by the pathologist at the end of the postmortem examination for forensic pathologists are not Sherlock Holmes. We report a case of a man who died immediately after trauma due to a natural disease.

\section{Case History}

A 70 year old man with a history of ischemic heart disease and a bypass surgery one year back has had a verbal argument with his neighbor. Following the argument it was witnessed that a stone being thrown at him. He was found collapsed few minutes later and was brought to the hospital. It was found that he had no vital signs but only a broad irregular rhythm in the electrocardiogram. Suspect was taken into custody and an autopsy examination of the body was ordered.

Information about the scene revealed no excessive blood loss. Post mortem examination revealed a laceration on the occipital area without any skull fractures or intra cranial injuries [Figure: 1] and a few grazed abrasions on the back. There was no pallor in his internal organs or conjunctivae. There was marked hypertrophy of the heart with ischemic scarring and an organizing myocardial infarction which was evident histologically [Figure: 2]. There were chronic hypertensive changes in kidneys.

Cause of death was ascertained as ischemic heart disease in a man with a scalp laceration.

\section{DISCUSSION}

Sudden natural deaths associated with minor trauma are not uncommon in forensic practice ${ }^{2}$. Though it is a common occurrence for a man to die suddenly following emotional disturbance and trivial trauma with pre-existing heart disease, ${ }^{3}$ the forensic pathologist is faced with a dilemma of explaining the court and the agitated relations how the former condition affect the latter resulting in death.

The head injury in this man is minor and only involves partial thickness of the scalp. Though rare, there are reported cases of sudden deaths associated with scalp lacerations. Cases have been reported where there is extensive bleeding from a scalp wound in association with other coexistent pathologies ${ }^{4}$. However, there was no autopsy evidence of pallor in this man to suggest considerable blood loss. Information obtained about the scene revealed that there was no excessive blood loss.

It is also predictable that this elderly person could have succumbed to his pre-existing heart disease at any moment ${ }^{5}$.The heart of this man was over $900 \mathrm{~g}$ and there was pre-existing scarring and an organizing myocardial infarction as well. Myocardial hypertrophy, scarring and infarctions are identified risk factors for sudden fatal arrhythmia $^{6,7}$.

However, the contribution to death from minor trauma and emotional disturbances associated with verbal arguments and pain cannot be excluded in this case. The stress of a verbal argument as well as any minor traumatic incident can lead to increased secretion of catecholamine which in turn can result in increased heart rate leading to fatal arrhythmia ${ }^{8,9}$. Possible proarrhythmic mechanisms associated with emotional and physical stress include alterations in autonomic tone manifested by decreased vagal and increased sympathetic components, this in turn increases the overall susceptibility to 
ventricular fibrillation specially in individuals with pre-existing cardiac disease ${ }^{10}$.

In forensic literature, sudden death of a man resulting from exacerbation of pre-existing heart disease that is induced by physical and/or emotional stress of a criminal activity of another person is sometimes referred to as "homicide by heart attack."11 In such circumstances it is necessary to prove that the emotional and physical stress associated with the criminal activity of another person was contributory to the death.

In this case, pathological investigations revealed that this man has a severe cardiac disease and a minor trauma. Historical investigations revealed that he had collapsed immediately after the assault. Based on scientific knowledge and considering historical and pathological evidence we can conclude that there is a definite contribution to his death from trauma. Thus, the cause of death was concluded as ischeamic heart disease in a man with a scalp laceration.

However, the contribution the pathologist can make in determining the manner of death is limited. Decision on culpability of the assailant is based on mensrea or the guilty mind which is the mental element of the offence. The mere simple non grievous nature of this injury does not necessarily mean that the assailant is not having an intention of causing death. It is beyond the expertise of the forensic pathologist to determine the knowledge of the assailant about the preexisting conditions of the victim and his intention of causing any act that would likely to cause death.

\section{CONCLUSION}

The decision on contribution of non grievous injuries to the death of this man with a lethal heart disease is crucial. Pathologist's contribution in forming opinions can be limited. The scientific knowledge of the pathologist as well as the legal evidence of mensrea or guilty mind may jointly play a role in prosecution of this case.

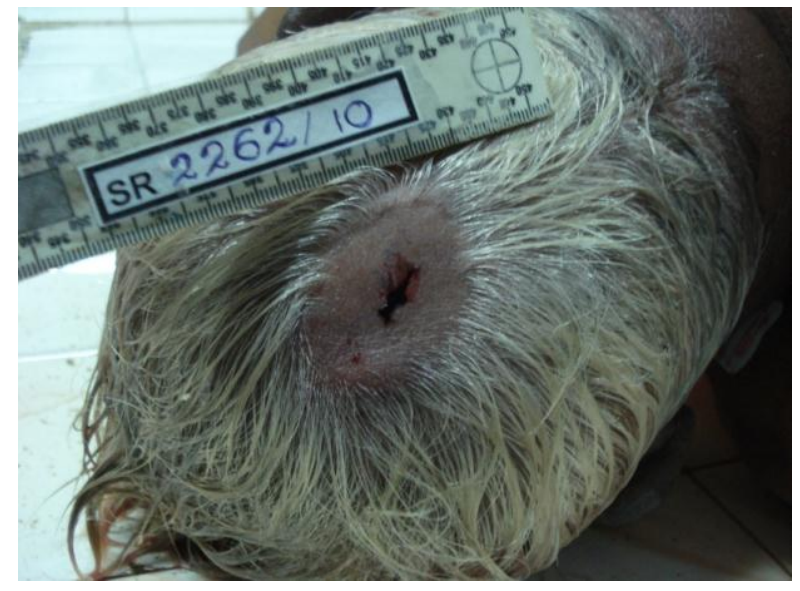

Figure: 1 - Scalp laceration on the occipital area

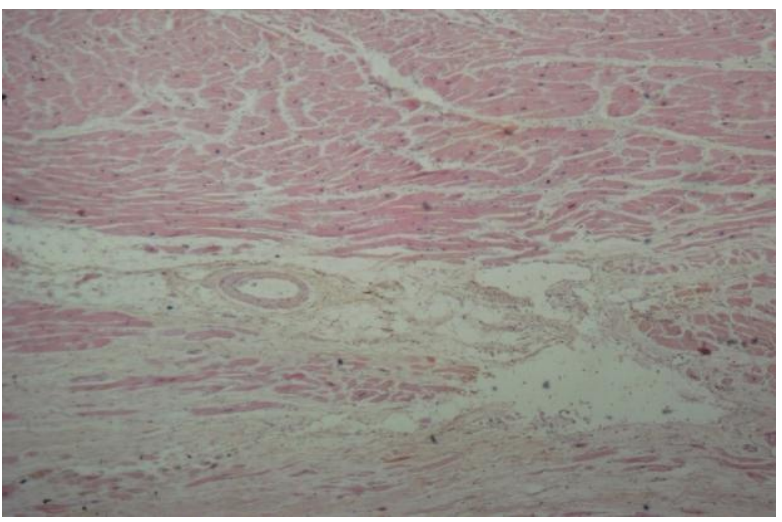

Figure: 2 Myocardial fibrosis with chronic inflammatory cell infiltration 


\section{REFERENCE S}

1. Fabio De Giorgio; Vincenzo Arena; Elisa Arena; Maria Lodise; Giuseppe Vetrugno; ArnaldoCapelli; Vincenzo L Pascali, Homicide by heart attack?, Legal medicine (Tokyo, Japan) Volume: 11, Suppl 1, S531-S532

2. Biagio Solarino, William Ralston, Kevin Youngerand Donna M. Hunsaker, Sudden natural deathin a suicide attempt, Forensic Science, Medicine, and Pathology, Volume 2, Number 3 / September, 2006, pp189-192

3. Oström M, Eriksson A. Natural death while driving. J Forensic Sci. 1987 Jul;32(4):988-98

4. J. R. Hamilton, J. P. Sunter and P. N. Cooper, Fatal hemorrhage from simple lacerations of the scalp, Forensic Science, Medicine, and Pathology, Volume 1, Number 4 / December, 2005, 267-271

5. H Eikki V. H Uikuri, Gustin C Astellanos, and R Obert J. M Yerburg, sudden death due to cardiac arrhythmias, N Engl J Med, Vol. 345, No. 20 , November 15, 2001 , 1473-1482

6. Steen Z. Abildstrom, Christian Torp-Pedersen and Lars Køber, Arrhythmic and Sudden Death in Chronic Ischemic Heart Disease-A Review of Epidemiological Data, Cardiac Electrophysiology Review, Volume 6, Numbers 1-2 / February, 2002, 5-8,
7. A V Ghuran and A J Camm, Ischaemic heart disease presenting as arrhythmias, British Medical Bulletin 2001; 59: 193-210

8. Kirchhof P, Klimas J, Fabritz L, Zwiener M, Jones LR, Schäfers M, Hermann S, Boknik P, Schmitz W, Breithardt G, Kirchhefer U, Neumann J., Stress and high heart rate provoke ventricular tachycardia in mice expressing triadin, J Mol Cell Cardiol. 2007 May;42(5):962-71,

9. DO Williams, TA Bass, H Gewirtz and AS Most, Adaptation to the stress of tachycardia in patients with coronary artery disease: insight into the mechanism of the warm-up phenomenon, Circulation 1985;71;687-692

10. Christine M. Albert, Claudia U. Chae, Kathryn M. Rexrode, JoAnn E. Manson and Ichiro Kawachi, Phobic Anxiety and Risk of Coronary Heart Disease and Sudden Cardiac Death Among Women,Circulation, 2005;111;480-487

11. Turner SA, Barnard JJ, Spotswood SD, Prahlow, JA," Homicide by Heart Attack" Revisited, Journal of Forensic Sciences (JOFS), Volume 49, Issue 3 (May 2004), 598-600 